\title{
Self-adaptation and Transnationality in Marjane Satrapi's Poulet aux prunes (2011)
}

\author{
COLLEEN KENNEDY-KARPAT*
}

\begin{abstract}
Marjane Satrapi's Poulet aux prunes offers an intriguing example of self-adaptation from comics to live-action film. This essay will consider how the Franco-Iranian Satrapi, within her dual role as self-adapter and transnational filmmaker, uses intertextuality and remediation beyond her own source text in ways that pointedly expand the transnational resonance of her film. These narrative and aesthetic strategies also extend to the film's paratextual discourses, namely, the extras available on the French DVD release of the film. The book, film, and DVD paratexts related to Poulet aux prunes thus form the core of this discussion of self-adaptation and transnationality.
\end{abstract}

Keywords Self-adaptation, comics, cinema, Marjane Satrapi, transnational, paratext.

One assumes that the usual course of film adaptation involves handing over a promising text - a novel, a story, a graphic novel, serial comics, etc.- to a team of filmmakers charged with reshaping the material to fit the dimensions and formal demands of the big screen. A related presumption holds that this transcoding - to use Linda Hutcheon's term - implicates, on the one hand, one or more 'original' authors and, on the other, an entirely new group of creative professionals. This process, as Shelley Cobb argues, might best be modelled as a conversation between authors and adapters, between source text(s) and their adaptations. While Cobb's metaphor offers a refreshing alternative to the rhetoric of fidelity criticism, how might we account for adaptations where this 'conversation' takes place with oneself? In other words, what might selfadaptation, where an author adapts his or her own previous work, show us about the way any adaptation works?

To examine this issue of self-adaptation, this essay offers a case study of Marjane Satrapi's Poulet aux prunes [Chicken with Plums], first released as a French graphic novel in 2004 and followed in 2011 by a (mostly) live-action film that Satrapi co-wrote and codirected in Germany's Babelsberg studios with a multinational cast. In addition to considering how Satrapi, within her role as self-adapter, articulates her authority in both media, this analysis also explores how the film adaptation of Poulet aux prunes uses intertextuality and remediation within the live-action format to expand the transnational resonance of her film. Intertextuality, in Gérard Genette's broadest formulation, designates the evidence of a hypotext (i.e., a preexisting source text) within a second, new text. Remediation, as defined by Jay David Bolter and Richard Grusin, involves grafting

*Faculty of Art, Design, and Architecture, Department of Communication and Design, Bilkent University.E-mail:kenkar@bilkent.edu.tr. 
the aesthetic or functionality of one, usually older medium onto the form of another, e.g., films remediating productions designed for the stage, or video games assuming the qualities of film. In Poulet aux prunes, both intertextuality and remediation affix Satrapi's own transnationality to the narrative and paratextual discourses of her film.

Satrapi's work sits at the crossroads of two lacunae formed by trends in studies of comics-to-film adaptations: on the one hand, the dominance of the superhero genre (in criticism as at the box office); on the other, the priority granted to Anglo-American comics. After a strong start as a noted author-artist in bande dessinée, ${ }^{1}$ a longstanding graphic narrative tradition in Francophone Europe, Satrapi co-directed a critically acclaimed, animated adaptation of her four-part Persepolis (books 2000-03; film 2007). Satrapi's work eschews the long-term seriality endemic to a great deal of mainstream comics production - e.g., the mainstays of the Marvel and DC catalogues or, for a European example, the ongoing adventures of Astérix and Obélix ${ }^{2}$ - a framework that aligns Satrapi's books more squarely with the closed narrative of literary novels. Like many of her forebears in the form, including Harvey Pekar and Art Spiegelman, her narratives are also deeply personal, with the term graphic memoir usefully describing the four-part Persepolis; however, the story in Poulet aux prunes depends far less than its predecessor on her personal and family history. This blend of personal narrative and niche commercial appeal puts the film adaptation of Poulet aux prunes in line with the production scope and market ambition of American comics-to-film adaptations like Ghost World (Terry Zwigoff, 2001) or American Splendor (Shari Springer Berman and Robert Pulcini, 2003).

Yet, compared to these American films, Poulet aux prunes stands out for Satrapi's transnationality and for the degree of control she exerts over the transcoding to a new medium. Comics scholar Bart Beaty recognises Satrapi as a prominent figure in an international group of artist-authors that he likens to 'the Antonionis, Bergmans, Fellinis, and Godards of the graphic novel age' (this allusion to celebrated directors is just one parallel that he draws between comics and cinema); yet of this sample pantheon, only Satrapi has used her background in comics to angle for the status of cinematic auteur (108). Other creators have certainly played a role in adapting their work for the big screen - e.g., Daniel Clowes co-authoring the screenplay for Ghost Worldbut Satrapi is among the rare author-artists to assume directorial duties. Frank Miller has also co-directed adaptations of his own work in Sin City (2005) and Sin City: A Dame to Kill For (2014), but his case as a comics-to-film self-adapter is complicated by the industry credentials and established production company that were brought to the table by his partner Robert Rodriguez, whose creative reputation stems from filmmaking rather than comics. In contrast, Satrapi and her co-director Vincent Paronnaud, both steeped in bande dessinée, entered filmmaking together for the first time with Persepolis; since then, Satrapi has leveraged this experience into a full-fledged directorial career that now stands completely independent of this partnership that helped launch it.

The decision to move away from the animation of Persepolis and instead film Poulet aux prunes with actors on a studio set introduces a host of issues that make this follow-up film a particularly rich text for examining how different narrative strategies and priorities emerge when an author-artist's drawings on a page inspire live action on a screen. Poulet aux prunes thus illustrates the four fundamental concerns that Pascal Lefèvre (2007) identifies in comics-to-film adaptation: adding or deleting source material to suit cinematic 
convention, page layout versus linear editing, photography/cinematography versus drawing, and film sound imposed on the 'silent' medium of comics. This essay will consider these four problems as manifested in the film adaptation of Poulet aux prunes and examine how Satrapi's solutions reflect the project's transnationalism.

\section{CUTS, COMPROMISES, AND CONVENTIONS: COMICS ON THE PAGE, CINEMA ON THE SCREEN}

The need to alter source material to suit the requirements of another medium is certainly not unique to comics-to-film adaptation, but among the four points of tension that Lefèvre describes, the question of adding or removing material is particularly likely to instigate debates about fidelity. Despite recent, determined efforts to manoeuvre the field beyond this persistent sticking point, fidelity remains both visible and contentious in adaptation studies; no consensus has emerged about how best to move past it, or even whether it must be surpassed at all. ${ }^{3}$ As the sense and significance of fidelity continue to evolve, self-adaptation offers a shortcut through some of its thorniest debates. When an author-artist becomes involved in the subsequent film adaptation of her work, accusations of 'betrayal' or 'infidelity' to the original suddenly ring hollow, since whatever changes have been made - and as Lefèvre emphasises, in transcoding there are always changes that must be made - it becomes difficult to take Satrapi to task for failing to respect her own work. ${ }^{4}$ Even if her adaptation falls below expectations, responsibility for these perceived shortcomings ultimately rests with her and not with other adapters' 'faulty' interpretation or 'excessive' liberties vis-à-vis the source text. An analytical focus on the strictly limited category of self-adapted texts offers a vantage point from which to examine the mechanics of comics-to-film transcoding - i.e., the transfer of narrative elements from the code $(\mathrm{s})$ of one medium into another - without needing to account for the conflicts or differences between multiple and/or media-specific creators.

In the filmed version of Poulet aux prunes, many of its alterations have little to no bearing on the book's core narrative arc, which recounts the final days of Nasser Ali, a musician and patriarch who resolves to die after losing the pleasure and solace he had found in his music. After a brief prologue shows Nasser Ali's funeral, the narrative rewinds to show, day by day, the eight days that transpired between his resolution and his death, during which he reflects on his past - particularly his youthful, doomed love affair with a woman (rather tellingly) named Irâne - and navigates difficult family relationships. In the film, the events of the third and fourth days are reordered, but presented basically intact. Further streamlining removes Nasser Ali's two older children and his younger sister (unfortunately cutting a revealing encounter with her in his penultimate day of life), and a friend named Manoutchehr, whose minor role is assumed in the film by Nasser Ali's brother Abdi. The remaining characters are subject to superficial adjustments like name changes, with the film generally preferring alternatives that gloss over the language gap for actors (and audiences, and critics) not fluent in Farsi. Thus, Nasser Ali's young son Mozaffar becomes Cyrus in the film, daughter Farzaneh becomes Lili, and wife Nahid becomes Faringuisse (which rings better in French than in English).

Less superficially, in a move that changes the very ontology of the story, the film elides any suggestion that these characters were based on real people. Following the tremendous success of her graphic memoir Persepolis, Satrapi based her follow-up book 
Poulet aux prunes very loosely on the life of her great uncle, a respected musician in 1950s Iran. But she admits to inventing most of his story: 'I saw a picture of my mother's uncle and they told me that he was a great musician. That when he was playing in his garden they would stop in the street listening to his music. And I saw some sort of melancholy and something in his eyes. [...] The rest is my story-things that I have heard, things that I have made up' (Mechanic). Elaborating on this modicum of knowledge about her uncle, in the book Satrapi blends elements of the fantastic with her family history, but she entirely removes this personal connection from the film. The graphic novel situates Satrapi as the narrator, although she does not reveal herself as such until well into the book, when the narration suddenly becomes first-person; the self-portrait that appears here would be familiar to anyone who would have read or seen Persepolis. The book describes her 1998 visit to Nasser Ali's youngest daughter (and her mother's cousin) Farzaneh. In revealing herself as the narrator, Satrapi frames the graphic novel through the lens of present-day perspective, thereby situating Nasser Ali's life and death - that is, the entire core story - as flashback. In contrast, the film, which lacks Satrapi's direct intervention in the present, grounds the action more firmly in the past. Both versions of the narrative make leaps through time, although in the film, flash-forwards to the future lives of Nasser Ali's children are made possible thanks to an omniscient and otherworldly narrator: Azraël, the angel of death, who comments on the action in voice-over before appearing on screen in the film's third act.

\section{INK ON PAPER MEETS THE CAMÉRA-STYLO: SEQUENTIALITY, CINEMATOGRAPHY, AND EDITING}

The use of live action rather than animation underscores the visual differences between comics and film. Both media are examples of what Karin Kukkonen calls multimodal storytelling, in which various semiotic codes, or modes are combined in a single, coherent medium. Each combines language and visuality in ways that can be transcoded to the other fairly directly: drawn, still images become cinematic (animated or live action) images; written language becomes spoken speech in dialogue and/or voiceover narration (35-36). However, the process of transcoding sequentiality - that is, how images precede and succeed one another in a reader/viewer's perception - is far less straightforward.

Sequentiality emerges very differently in comics and film, a divergence significant enough that Lefèvre uses it to name an entire category of problems in comics-to-film adaptation. Primarily concerned with the question of comics' page layout versus conventional, linear film editing, Lefèvre emphasises that 'the specificity of the [comics] medium, namely that the whole sequence is at once present for the reader, is important[;] unlike the movie spectator, the comics reader can scan the images at his or her own speed to make sense of the whole' (2011:29). The simultaneity of the panel form of comics allows for a visual experience generally not available to cinema; 'while the shutter speed of a photo can tell us the precise time period recorded by the camera, there is no objective way to determine the time period encapsulated by a handmade picture', nor is there a rigidly fixed order in which parts of that picture should be read (Lefèvre 2011: 23-24). A reader of comics inevitably takes in a whole page at once, even as individual panels are (generally) presented and eventually processed in 
a legible sequence, although there remains the potential to create a more ambiguous relationship to sequence and, thus, to time. In other words, the comics page is (or should be) greater than the sum of its panels. In film, the interplay between part and whole comes from juxtaposing individual shots that are generally intended to fill the screen one at a time, building a sequence whose order is strictly predetermined by the filmmakers, and conventions of screening (at least in commercial theaters) require obeisance on this point. While cinematographic techniques like split-screen, which joins separate shots together within the frame, are far from unprecedented, their rarity indicates that such visual approaches are more aptly classified as an example of remediation than as devices native to conventional cinema.

An author-artist first, Satrapi's intimate awareness of the kind of sequentiality specific to graphic storytelling shines through in her cinematic self-adaptations. In the graphic novel Poulet aux prunes, arguably the clearest, and certainly the most frequently recurring use of layout to convey meaning appears in the headings that mark each day that precedes Nasser Ali's death; in the film, these take the form of intertitles. In the book, their format is always the same: centred on the page, against a black background, is a view of Nasser Ali from roughly the chest up, though his position and the angle from which we see him both change. In some he is lying down, in others upright; in some we look down at him, in others we look straight on or even slightly up at him, as on the sixth day (discussed below). At the bottom of the frame, block capital letters, in white against the black background, give the day in ordinal sequence, proceeding chronologically after the prelude depicts the endpoint, i.e., his funeral. Just below the frame, in slightly smaller print, black letters spell out the exact date. The only variation on this format comes on the date of his death, which shows Nasser Ali in reverse contrast, a black figure outlined in white, embraced by a white silhouette that represents his lost love, Irâne (her hairstyle offers the crucial clue to the silhouette's identity). Without exception, these headings appear on the right-hand page of the book, always juxtaposed with the content of the preceding page. These headings thus present the end of one day while announcing the next, using the medium's simultaneity to enforce a sense of continuity over time.

Because these juxtapositions invite closer visual analysis, we will consider Day 3 and Day 6 as examples. The page before Day 3 shows Nasser Ali experiencing a moment that serves as an elegy to earthly pleasures after a visit from his brother Abdi. Trying to shake Nasser Ali's will to die, Abdi had mentioned a Sophia Loren film playing at the cinema. While Nasser Ali refuses his brother's invitation to see it, after Abdi leaves Loren appears to him as he ruminates on his hunger and dreams of his favourite food, the eponymous chicken with plums (Figure 1). In his mind - the graphic novel demarcates this departure from the 'real' with distinctly rounded panel edges-Nasser Ali stares intently at a platter full of chicken and trimmings, which before his eyes takes the form of a woman's breasts, then shoulders, then her head, panel by panel replacing the food with the larger-than-life body of Sophia Loren. Finally, in the page's largest panel Nasser Ali lies with his eyes closed and his head cradled between her breasts. Below this sensual image, the text reads: 'At dusk on the second day, Nasser Ali Khan remembered what pleasure could be. Overnight, his bitterness disappeared. He fell asleep peacefully'. On the following page, the chapter heading for the third day, Nasser 

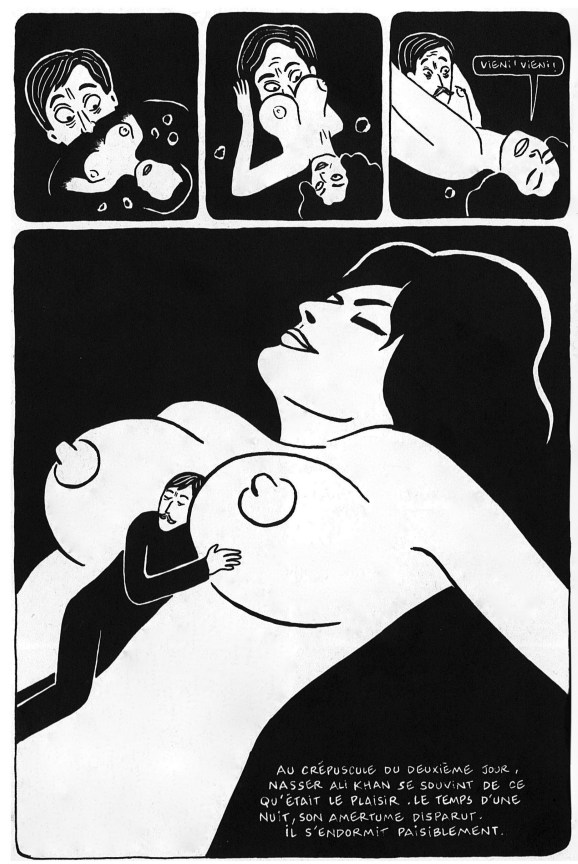

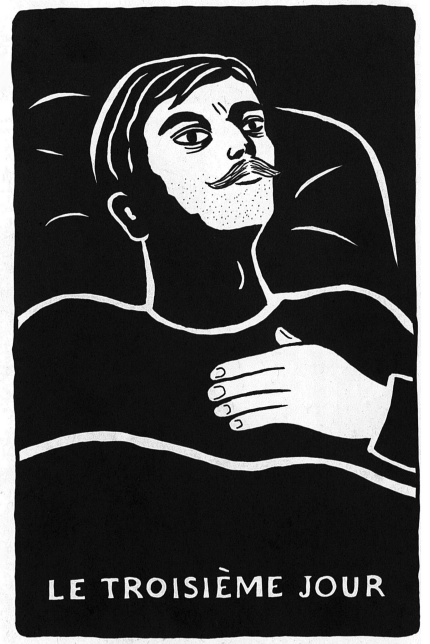

17 NOVEMBRE 1958

Figure 1 The conclusion of Nasser Ali's Sophia Loren fantasy, and the beginning of Day Three. Reproduced from Poulet aux prunes (2004) by Marjane Satrapi with permission from L'Association.

Ali lies awake in bed with an upturned, smiling face and his left hand draped across his own chest in a gesture that mirrors his caress in the previous panel. His face and body in the header are also angled in a way that mirrors Loren's. However, in contrast to the full clarity given to her imagined, exaggerated body, prominent shadows obscure Nasser Ali's jawline and cast shadows over parts of his nose and brow. Still, the source of his pleasure on this third day is clear, and the panels on the following page resume the action from this point of relatively optimistic perspective.

Nasser Ali's fantasy encounter with Sophia Loren exemplifies the difficulty of transcoding drawings into live action cinematography, particularly depictions of unrealistic and subjective daydreams. The film cuts the reference to chicken with plums at this point in the story (possibly because filming the transformation described above would have demanded too high a budget), but creates in its place a new entrance for 'Sophia Loren'. In the film, the brothers' conversation ends with a high-angle two-shot in deep focus: Nasser Ali sits slouched on his bed to the left of the frame, while Abdi stands in a close-up that occupies the entire right half of the frame. After a fade to black signals a turn to subjective experience, the screen fades up on a pair of doors opening to a bright white light that casts a shadow of a voluptuous woman on the floor. The camera slowly tilts up as she steps forward, reaching her shoulders before a match-on-action cut shows her high-heeled shoes striding across the floor. Cut to Nasser Ali in bed as he turns toward the light, and an eyeline match picks up the tilting shot of the walking woman, finally bringing the camera up to show an invisible face, with halo-like backlighting on 
her hair. The shot-reverse shot editing continues, as the woman removes her dress. Her face remains obscured, but the white light illuminates the bare skin of her body. In their stark, black-and-white contrasts and clear, strong lines, these shots resemble Satrapi's drawing style more than any other live-action sequences in the film. Her dress drops to the floor in the centre of the frame, then the camera tracks with her from behind as she steps towards Nasser Ali's outstretched arms (Figure 2). The perspective seems to shift; with her bosom in close-up - in the (arguably) family-friendly film, she wears a brassière - she leans in, arms spread, to receive Nasser Ali, who now appears smaller while the bed behind and beneath him has grown larger. A low, thrilling voice purrs 'Vieni, piccolo' - the sudden, sexy burst of Italian making clear, if it wasn't already, that this woman represents Sophia Loren.

Nasser Ali finally makes contact in two shots, cross-faded into one another, that feature a larger-than-life model of a female torso replete with gargantuan breasts (Figure 3). Nasser Ali first nestles his face between them, then the second shot shows a close-up of his hand in mid-caress, both shots echoing the visual emphases of the book. This shot of hand on breast cross-fades with a shot of the fireplace burning in his bedroom, which in turn fades to black before an intertitle announces the third day.

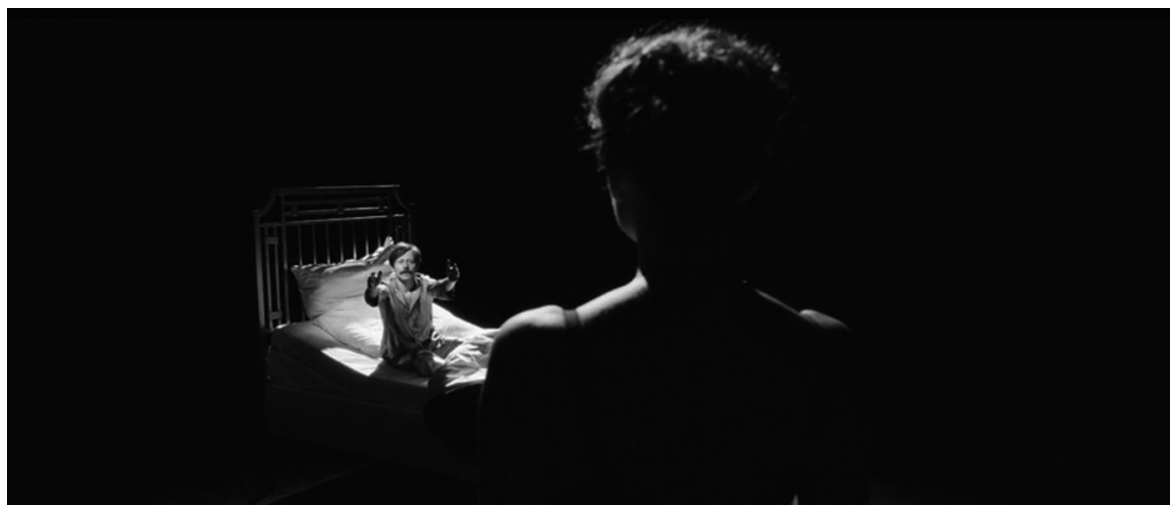

Figure 2 Nasser Ali (Mathieu Amalric) opens his arms for 'Sophia Loren' in Poulet aux prunes (2011)

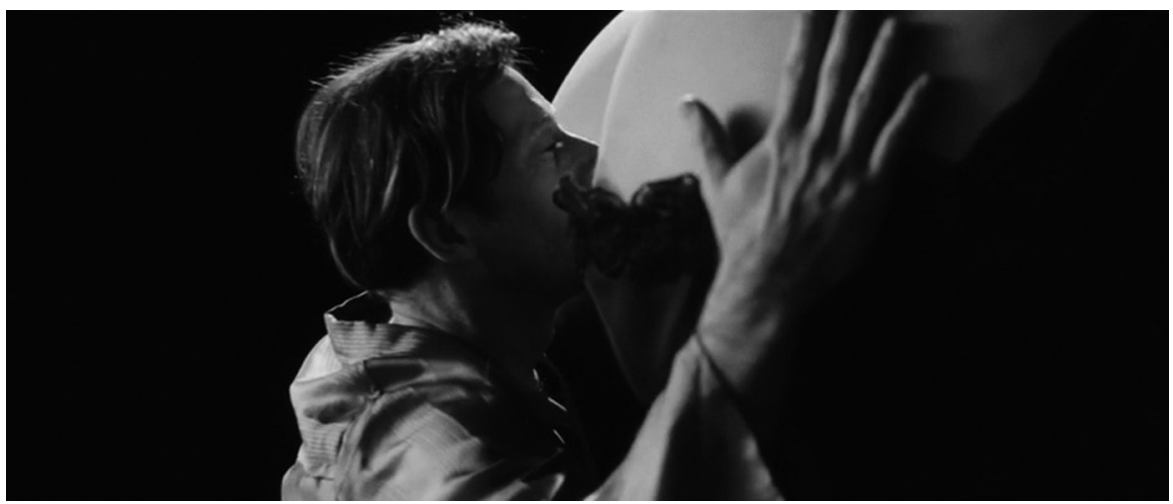

Figure 3 Nasser Ali (Mathieu Amalric) makes contact with his fantasy in Poulet aux prunes (2011). 
In some ways, Nasser Ali's fantasy reflects the limitations of filming live action, using only practical effects to convey physical impossibilities. Still, the sequentiality of this moment effectively transcodes the character's experience into cinematic conventions, while the mise-en-scène and cinematography maintain a visual connection to Satrapi's black-and-white drawings.

By Day 6, a more sombre tone has taken hold, with thoughts of death replacing Nasser Ali's memories of pleasure. In the book as in the film, the fifth day unfolds mostly as a flashback to his mother's final days, marking the narrative's metaphysical turn with the figure of a dervish in attendance at his mother's burial. Among other words of wisdom, the dervish assures Nasser Ali that he was right to honour his mother's request to stop praying for her life, because it was her time to die. When the graphic novel returns to the present at the end of the fifth day, Nasser Ali wonders if someone's prayers have been keeping him alive. The final panel (Figure 4), which occupies the entire page, confirms this suspicion, its caption reading: 'The night of 19 November 1958, a gloomy silence reigned over his house. Nasser Ali Khan was right. Someone was praying for him'. An outside view shows the windows of the house, squared and lined up like panels within the larger panel, all dark except for two: one on the ground floor shows Nasser Ali's room, identifiable thanks to the distinctive curtains, clearly lit but with its occupant nowhere in sight; meanwhile, the top right window shows Nasser Ali's young son with his hands turned upward in prayer and a sorrowful expression on his face. Visually, the juxtaposition of this panel with the next - in which Nasser

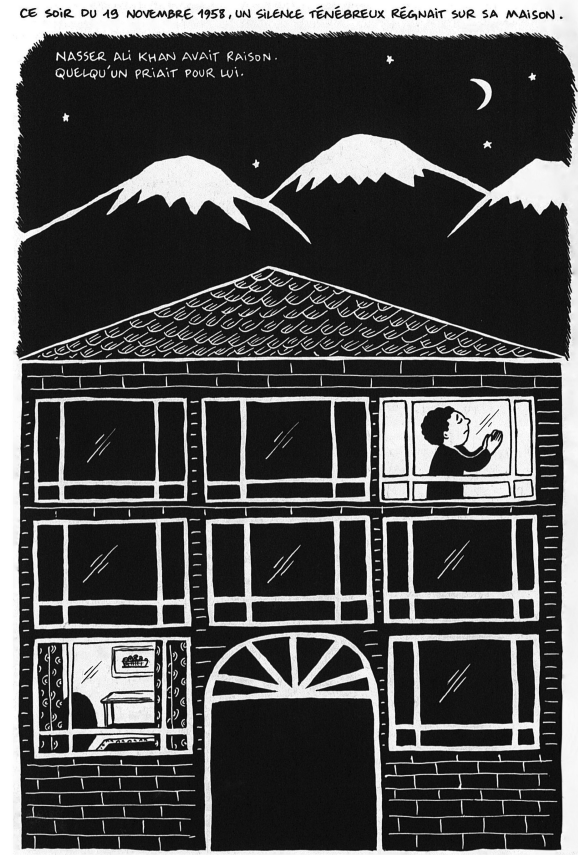

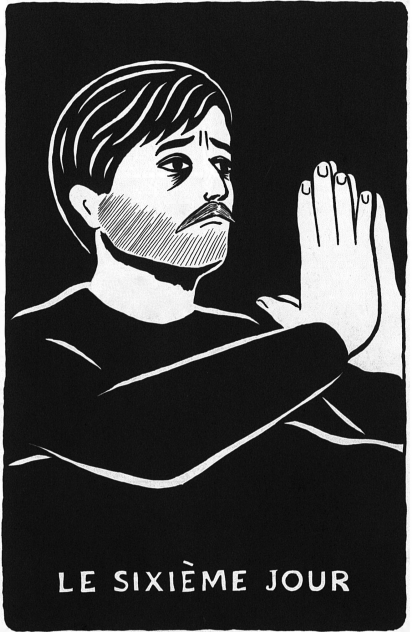

20 NOVEMBRE 1958

Figure 4 Joined and separated through prayer: Nasser Ali and his son. Reproduced from Poulet aux prunes (2004) by Marjane Satrapi with permission from L’Association. 
Ali joins his hands in prayer to mark the start of the sixth day-establishes a parallel between Nasser Ali and his barely tolerated young son while also disproving Nasser Ali's assumption that his beloved daughter must have been calling for divine intervention. However, on the following page, the appearance of Azraël, the angel of death, reveals that the purpose of Nasser Ali's prayer is directly at odds with his son's, redirecting the reader away from this momentary glimpse of common ground.

The filmed Poulet aux prunes transcodes the chapter heading panels as intertitles, with white-on-black, all-caps lettering that indicates only the day in ordinal sequence. The film takes no note of exact dates, and this text is never superimposed on any image, using this separation of the text from action shots to underscores the film's linear sequentiality. These intertitles, used as cinematic bookends, mark each new instalment within the master arc, transcoding the graphic novel's visual parallels into the cinematic language of montage and cinematography. For instance, the camera motion seen in the shots before and after the sixth day's intertitle emphasises the same father-son connection illustrated in the book. The final three shots of the fifth day show, first, a bird's eye view of Nasser Ali in bed at the centre of the frame, then tracks backwards before tilting up and fading to black to set up an invisible edit. In the next shot, the camera completes its upward tilt, then tracks right, passing over Lili and Faringuisse asleep in their beds. The choice to have the camera 'pass through' the floor and walls of each room visually recalls the gutter space of comic panels, even though the book relies on the simultaneity of juxtaposition rather than the sequentiality of successive panels to represent this narrative moment. Continuing the same tracking shot, the camera passes into the last room and stops on Cyrus at prayer, situating him in the top right of the frame. The final shot cuts away to the house's exterior, the camera looking in on Cyrus through the window as it tracks backwards and slowly pans left, stopping again with Cyrus in the top right corner in a frame that echoes the layout of the graphic novel (Figure 5).

The two backwards tracking shots that begin and end the sequence set up the parallel between Nasser Ali and his son, a connection that the sixth day's opening shot reinforces by tracking backwards once again. This shot opens on Nasser Ali dozing in bed before the camera pulls away at a similar pace and angle to Cyrus's window shot - then

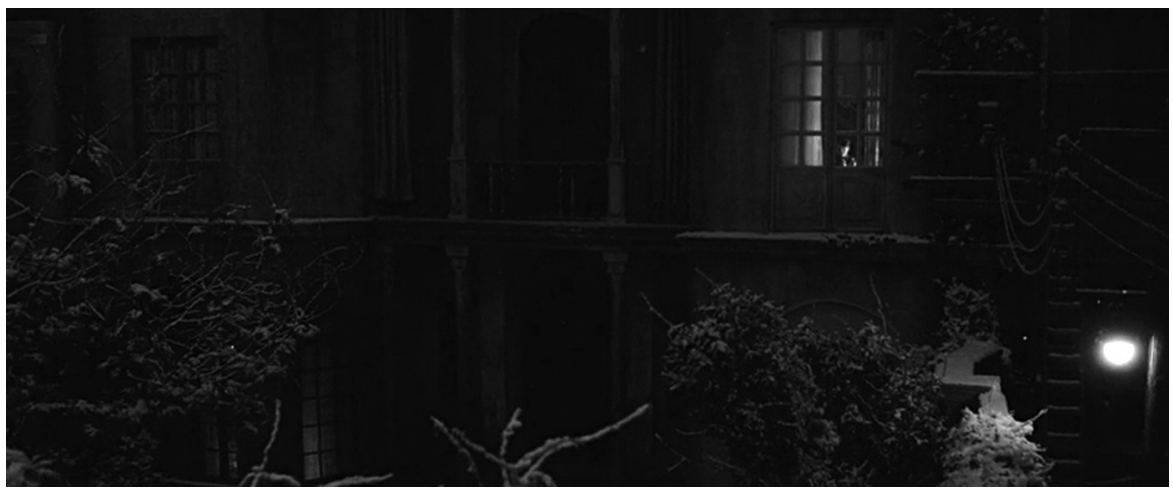

Figure 5 Cyrus at prayer in Poulet aux prunes (2011), the mise-en-scène an echo of the corresponding moment in the book. 
the camera pans sharply to the right to reveal Azraël at the foot of his bed. As with the Sophia Loren fantasy, transcoding this visual connection between the two characters requires and delivers a sequentiality specific to cinema.

As these examples make clear, Satrapi and Paronnaud bring to their film many of the concepts that the graphic novel expresses and emphasises through its visuals. As Lefèvre anticipates, the constraints of live-action cinema force some changes, yet a close reading of sequencing and cinematography does not suggest a complete turning away from the source. This question of visual aesthetics - that is, how the style, nuance, and spirit of the source text can be transcoded effectively, though not always strictly 'faithfully', from page to screen - has proven crucial to the practice and critique of comics-to-film adaptation. Thomas Leitch asserts that no comics-to-film adaptation has tried to assiduously replicate the visual feel of its hypotext(s), ${ }^{5}$ yet some films use visual cues to articulate their relationship to their source material (199). For his part, Lefèvre advises filmmakers to find an indirect, visual way to recall rather than replicate their source(s), conceding that absolute visual fidelity remains a nearly impossible goal due to the differences between drawings and photography. If these differences in format prove insurmountable, Lefèvre suggests that 'the deliberate choice for a clearly artificial, but credible world seems to work well' as an alternative to strict fidelity (2007: 10).

If Satrapi had wanted to make another Persepolis - that is, to animate Poulet aux prunes in the style of her drawings - she obviously had the capacity to do so. Instead, as Lefèvre advises, she adopts an approach that embraces artifice not through the medium of animation, but through an intertextual bricolage that assembles several transnational source texts to complement her own material. Satrapi told Mother fones that the film's look was inspired by mid-century Hollywood melodrama: Michael Powell, Emeric Pressburger, and Douglas Sirk. 'But in Douglas Sirk movies', she notes, 'you never have a moment when the father wants to give the last word and the kid farts' - which, of course, is the fate of Nasser Ali. The Technicolor palette and unbridled melodrama of Poulet aux prunes reflects Lefèvre's notion of a 'clearly artificial, but credible' live-action adaptation that captures the spirit of the book if not its exact visual contours. Far from a pure pastiche of these films, Poulet aux prunes augments the studio artifice of its reconstruction of 1950s Tehran with occasional forays into remediation that lend touches of whimsy to the film's rather dark conceit (it is, after all, a film about suicide by sheer will).

It is not unusual for a comics-to-film (or, indeed, any) adaptation to use remediation to recall the medium of its source material. Some of these strategies have even become clichés, e.g., the fairy tale adaptation whose opening sequence shows a book cover opening to reveal the characters. As an example of this in comics-to-film, Ang Lee's Hulk (2003) features sequences inspired by the panel style of The Incredible Hulk series. While Poulet aux prunes also recalls its original medium, the film extends its remediating impulse to areas beyond its primary source text, using media ranging from animation to the photographic slide show to present vignettes that digress from or add depth to the narrative's focus.

Animation offers the closest analogue to the film's source material, with a handful of fully or partially animated sequences appearing in the film. The animated opening credit sequence recalls the film version of Persepolis more clearly than it anticipates the principally live-action aesthetic of Poulet aux prunes. The moon's face in particular reflects 
Satrapi's style (particularly in the rendering of the eyes) — an image that, not coincidentally, appears alongside the title card that contains the directors' names and a note that Satrapi's graphic novel inspired the film. When Azraël narrates his encounter with Monsieur Ashour, his retelling accompanies a fully animated, two-minute sequence that once again features Satrapi's signature look. Azraël tells the same story in the book, but the film develops its corresponding visuals in greater detail, including the transition device of a pop-up book (another remediation) to introduce and conclude the episode.

The most thematically striking example of remediation in Poulet aux prunes concerns Cyrus, a reliable source of comic relief, whose future exploits are detailed in a flashforward based roughly on the book, but with a few significant changes. This sequence incorporates two different media aesthetics to present Cyrus's future. The first, narrated in voice-over by Azraël, shows a series of brief shots combining the choppy, unnatural motion of silent film with blurry framing and editing designed to resemble a slide show, complete with wipe transitions and the distinctive clicking sound of the carousel. As a medium, slides connote a passive audience gazing at images that either recount the narrator's personal experience (e.g., a vacation) or present material in a pedagogical context (e.g., reproductions of artwork shown in a classroom). The purpose here reflects both of these connotations, as Cyrus's personal life story takes on a didactic tone that reaches its climax in the epilogue delivered by his sister Lili (Chiara Mastroianni). The final slide becomes the establishing shot for the second part of the sequence, which remediates the classic American television sitcom. The screen dimensions broaden, and its frame becomes clear with corners rounded off to resemble a cathode ray screen. Azraël's voice-over disappears, and the characters' dialogue - suddenly in English - takes over the narration within the diegesis. The sense of parody becomes even stronger, with Gyrus and his family caricaturing the standard sitcom household: a comfortable (if tacky) suburban home; three children on the couch intoning their greeting in unison when Cyrus arrives home; a slender, vacantly smiling wife offering him a cold drink. As with the slide show, exaggeration dominates both action and style: the line readings, the mise-en-scène, the extradiegetic sound, even the camera work. As in the book, the sequence finally zeroes in on Cyrus's daughter to deliver its punch line. ${ }^{6}$

The remediation that conveys Cyrus's future helps lift this story's wider implications to a transnational level. In the graphic novel — where Satrapi's role as narrator suggests a closer resemblance to actual family history - Nasser Ali's son stays in Iran for his university education and marries a classmate, who gives birth to three children there before the onset of war compels the family to immigrate to California. In the film, Cyrus interrupts his university studies in Iran to transfer to 'a mediocre university in Wyoming', where he meets his American wife. While most of the key details of Cyrus's life match the outline given in the book - still three children, still the same suburban American dream, still the same fate for his daughter - the transplantation of an entire Iranian family to America resonates very differently than Cyrus's individual assimilation by marriage to an American. This change implies that this culturally mixed marriage, rather than the trauma of the whole family's deracination, has condemned the next generation to moral corruption as signified in both texts by extreme obesity and unplanned pregnancy. This very different tale of migration hews to the script of the 
lone immigrant making his way through a new land, a trajectory underscored and pointedly ridiculed by the overdetermined sitcom aesthetic.

In the film, Lili comments disdainfully on her brother's story in an epilogue whose visuals recall her own melancholic, eminently cinematic flash-forward; the contrast made visible by this sudden return to a cinematic aesthetic signals the importance of the remediation that precedes it. By repurposing the visual contours of the American sitcom - a television genre with clear exportability and, therefore, transnational presence - the film introduces an immigration narrative that follows an implicitly American formula. These adjustments to Cyrus's fate and their transcoding through remediation aesthetics align with the film's refraction of intertextual influences and transnational contexts.

\section{TALKING PICTURES: INTRODUCING SOUND TO A 'SILENT' SOURCE TEXT}

The moment in Cyrus's flash-forward where the dialogue abruptly shifts into English underscores how sound can be used to add new layers of meaning when adapting comics, a medium that, as Lefèvre emphasises, is essentially silent. At the most obvious level, transcoding abstractions of sound into a medium where sound can stand for itself means that incidental effects - e.g., footsteps on pavement, cars in the street - may be integrated without major quibbles. However, sounds like voices and music require more attention to nuance, and their integration within the diegesis and/or as extradiegetic sound introduces a host of questions that assume even greater importance when the narrative centres on music, as in Poulet aux prunes.

One of the most significant adjustments made for the film profoundly affects its use of sound: Nasser Ali, a celebrated musician, plays the violin instead of the traditional tar as described in the book, leaving the character with a less culturally specific touchstone. Fame as a tar player is inextricably bound to the culture(s) familiar with the instrument, but violinists claim a much farther reach (although its musical style differs widely between and even among cultures). When Nasser Ali takes pains to travel in search of a new instrument, calling it a Stradivarius immediately conveys its quality whereas an equivalent indication for a tar would be lost on an international audience; indeed, in the graphic novel, Satrapi adds a footnote that compares a tar yahya to a Stradivarius. Unable to support such explanatory glossing, the limitations of film as a medium thus encourage changing the instrument outright.

Having a musician as a main character gives music a crucial role in Poulet aux prunes. The film's diegetic music strongly depends on standard techniques like post-synchronisation to achieve verisimilitude, meaning the music on the soundtrack came from an actual musician behind the scenes rather than the actor who plays a musician on screen. ${ }^{7}$ In contrast, extradiegetic music, unbound by a similarly intimate connection to the characters and action on screen, can be used for many different purposes. In Poulet aux prunes, extradiegetic music shapes the film's cultural setting in part by reinstating a key element of the graphic novel: the tar, which reappears in the film's soundtrack via its musical cousin, the sitar. This musical representation helps set the scene despite the absence of Nasser Ali's tar in the visual mode. The opening credits begin with a sitar solo backed by percussion, then joined by orchestral accompaniment that gradually 
overtakes the sitar. Indeed, most of the film's extradiegetic music, relies on the violin, which emphasises Nasser Ali's musicianship, and the piano. One remarkable digression from this pattern comes when the young Nasser Ali first encounters Irâne in the streets of Tehran and follows her until she reaches her father's clock shop. His pursuit is punctuated by a thrumming drum solo, then, face to face in the shop, a delicate duet between piano and vocals mark this moment of instant attraction. This musical motif returns during their final encounter, which precipitates Nasser Ali's loss of musical pleasure and, thus, inspires his decision to die. This moment is shown at the beginning and again at the end of the film, but the more developed second flashback aurally echoes their first meeting: percussion to accentuate their respective movements in the street, combined with heightened drama in the vocals and orchestration that crescendo until they come face to face.

As for the sitar, it returns in the film's third act to underscore moments of the narrative that depend on cultural specificity. Serving as a sound bridge, a sitar solo brings Nasser Ali back to the present after a flashback to the mystic at his mother's funeral; then, during Azraël's visit on the sixth day, sitar music bookends the tale of Monsieur Ashour. Yet the extended flashback on the eighth day that traces Nasser Ali and Irâne's romance and the aftermath of its rupture features lush and emotional music featuring an orchestra with vocals, but no sitar. This use of music underscores what Satrapi considers the most universal element of her story: that "when your heart is broken, you can be rich, poor, whatever - a broken heart, we are all equal in front of it. And I think there is no subject more serious' (Mechanic). Considering this experience of lost love as something that transcends culture counterbalances the setting in Poulet aux prunes, encompassing both cosmopolitan appeal and local specificity. This combination, suggested by Satrapi as a transnational filmmaker and articulated in the narrative, also informs the film's paratextual discourse. The paratexts of Poulet aux prunes are the focus of the next section.

\section{ARTICULATING TRANSNATIONALITY AND NATIONAL SPECIFICITY THROUGH PARATEXTUAL DISCOURSE}

In the inaugural issue of Transnational Cinemas, Will Higbee and Song Hwee Lim identify three approaches to transnationality in film. One approach is defined by regional cinematic activity among culturally related nations, e.g., transnational Chinese cinemas, which does not describe Satrapi's work, but Poulet aux prunes encompasses both of the other approaches: on the one hand, the transnationality of filmmakers hailing from postcolonial, diasporic, or exiled populations; on the other, transnationality as transcendence of the boundaries of national film traditions, a conceptualisation that considers such divisions to be increasingly arbitrary in contemporary film production (9). Satrapi's connection to her homeland of Iran and her eventual migration to Europe form the very subject of Persepolis, and she makes these roots just as clear in Poulet aux prunes; meanwhile, the production of Poulet aux prunes makes it difficult to categorise under a single national cinema, thus affixing the transnational label to filmmaker and film alike. However, as this section will explore, the paratextual discourse that supports and informs Poulet aux prunes never takes this dual transnationality for granted. 
As prime examples of paratexts - defined here as texts that are peripheral but also related to a featured text, and can influence the interpretation thereof-DVD extras play a crucial role in the life of a feature film, as Jonathan Gray argues in Show Sold Separately. No longer the exclusive province of collectors' or anniversary editions aimed at existing, invested fans, DVD extras have become a mainstay of home cinema for many types of viewer; indeed, by targeting the widest possible audience, these extras work to frame their feature film's preferred interpretation(s) as defined by the filmmakers and their production team (Gray 89-90). This accumulation of supplementary materials creates, according to Gray, a sense of 'authenticity' for the featured text and helps establish, to borrow Walter Benjamin's term, its 'aura' (83). For the most part, the supplements provided on the French DVD release of Poulet aux prunes are standard fare: a making-of titled '44 Days with Chicken with Plums' (its English title suggesting that it may have been made for promotional use outside France); three deleted scenes; a gallery of more than forty production photos; a selection of animatics and test shots; the promotional trailer; and the most unique supplément, a fifteen-minute featurette listed as 'Conte iranien [Iranian tale]'. While the range and structure of these extras contain few surprises - except the Conte iranien, as will be argued below - they position Poulet aux prunes as a celebration of international cooperation at the level of production while mediating its vision of Iranian culture almost exclusively through Marjane Satrapi as its primary auteur.

As discussed above, co-directors Satrapi and Vincent Paronnaud both came from the world of French bande dessinée to collaborate on Persepolis, their début film, and continued their partnership to direct Poulet aux prunes. While Satrapi's solo authorship of the books might cast doubt on the extent to which these films should be seen as collaborative efforts, the DVD extras for Poulet aux prunes make a special effort to affirm their equal partnership. The photo gallery of cast and crew shows the most objective balance, including the same number of photos (five) of each director working separately, and four of them working together. However, these photos also depict an unmistakable division of labour that puts Satrapi in charge of people, while Paronnaud deals with objects (camera, set pieces, etc.). Satrapi's extraversion, merely suggested by these snapshots in the photo gallery, ends up dominating the making-of featurette, in which her interactions and commentaries consume far more running time than the brief interview with a camera-shy Paronnaud, who asserts that their opposite personalities are what make them successful co-directors.

Contradicting this carefully constructed impression of a balanced contribution, in other paratexts Satrapi embraces her role as linchpin of the film's transnationality. Although her personal history already makes her a transnational filmmaker, the extras also show her expertly navigating a multicultural, multilingual set. In '44 Days with Chicken with Plums', Satrapi speaks English, German, and French (though never Farsi!) depending on the language of her interlocutor and/or the situation on set. For example, she conducts interviews in both English and French, but addresses a group of German children on set in their native tongue. In her interviews, she praises the studio experience at Babelsberg and explains that their choice to film outside their home city of Paris was made in the hope of improving their focus on the filmmaking process. Apparently, this is not a typical strategy; the film's German production designer 
Udo Kramer enthusiastically declares Poulet aux prunes to be his first 'French movie' and claims that its larger-than-life, melodramatic aesthetics make it different from German productions. National essentialism aside, including Kramer and other members of the crew in the making-of ultimately influences the audience's assumptions about a film's authorship; as Gray points out, 'introducing viewers to the many artists behind the film [...] serves to expand our understanding of who 'counts' as an author, potentially undercutting the myth of the single author' (100). Having two directors on a single film already calls into question the assumption of a lone auteur; however, Satrapi's privilege as self-adapter gives her an edge in terms of perceived authority over the finished work that is strengthened by her personal connection to her story and its cultural setting. While the paratexts work to expand the film's transnationality at the level of production, the cultural specificity of the narrative must necessarily - and somewhat paradoxically - come from Satrapi, the inherently transnational filmmaker.

The clearest acknowledgment of Satrapi's role as purveyor of Iranian cultural knowledge is the 'Conte iranien', a fifteen-minute soliloquy in which she outlines the diverse sources of inspiration behind Poulet aux prunes. Eschewing nearly every convention of cinematic narration, this featurette has no set, no organising narrative structure, minimal editing, and utilitarian (which is not to say bad) lighting. The camera never moves. Dressed in black, Satrapi sits screen left and looks directly into the camera as she speaks; sitting screen right is Mathieu Amalric, sporting a full beard and a rumpled grey shirt (neither of which featured in his on-screen wardrobe for the film), his gaze trailing off to one side of the camera (Figure 6). On screen, the viewer sees Satrapi and Amalric together, although each was evidently filmed with a different camera and joined in post-production. At the beginning and end of her discourse, Satrapi directly addresses Amalric as Nasser Ali, although he does not speak until the very end. This spare setup, visually unappealing in itself, practically demands that its viewers relinquish

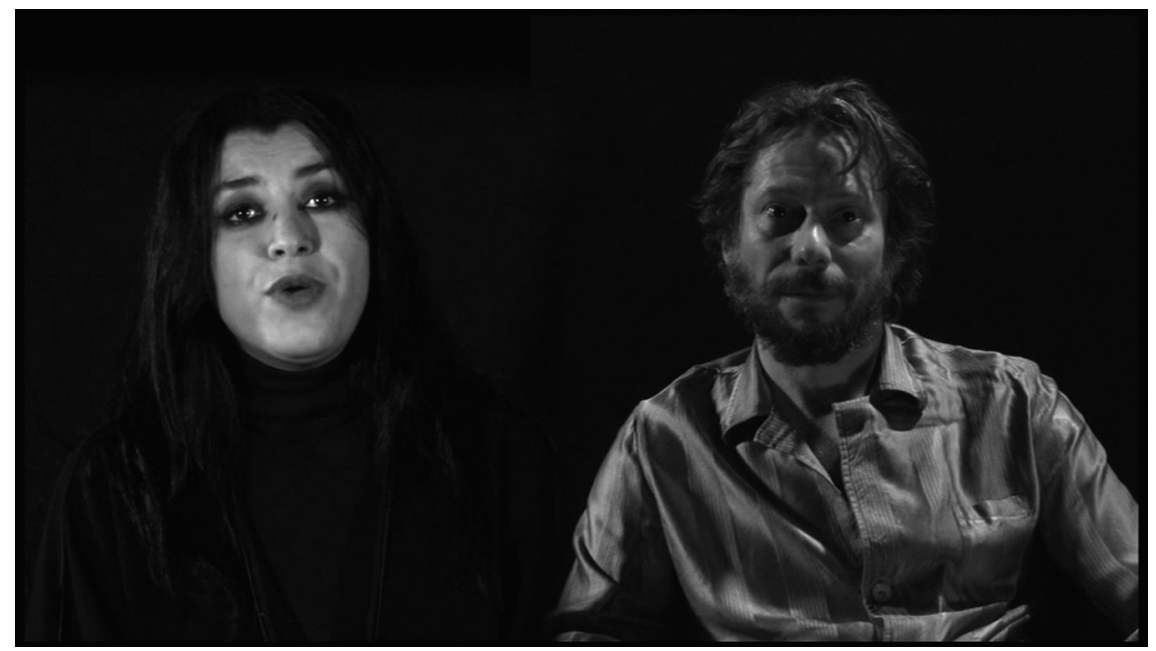

Figure 6 Marjane Satrapi and Mathieu Amalric in the "Conte iranien" featurette of the Poulet aux prunes DVD released in France (Wild Side Video, 2011). 
any expectation of visual stimulation - a very big hurdle to clear for a DVD extra - in order to focus instead on Satrapi's spoken words.

This speech, which comes off as carefully curated if not perfectly scripted, combines vignettes of family lore with snippets of literary history and folk culture, merging once again the specific (family) and the general (culture). Laying broad groundwork, Satrapi recounts some of the popular fables that explain the mysticism and non-Western philosophies that inform her perspective: the story of Monsieur Ashour who tries (and fails) to flee Azraël; the men who feel an elephant in the dark (featured in the book but not the film); and, in the only story unique to the featurette, a man who ill-advisedly befriends a bear. At one point, she speaks Farsi - the only moment in all of the extras where she does so - and immediately translates it into French. She introduces major Persian poets Omar Khayyam, Attar of Nishapur, and Rumi, briefly discussing their attitudes towards life, death, and spirituality. Linking this cultural framework to stories about her family, the viewer learns that Nasser Ali's prayers that kept his mother alive were inspired by her own great-grandmother, a mystic beloved by her grandson (Satrapi's uncle), who tried the same strategy until his grandmother asked him to stopshe died shortly thereafter. The coup de foudre that Nasser Ali feels when he first meets Irâne was inspired by Satrapi's grandfather, who glimpsed 'a nice pair of legs' in the street, followed them, and discovered that those legs belonged to the love of his life. Her grandparents' real-life tale of love at first sight ended more happily than Nasser Ali's fictional one, but perhaps more significantly, her retelling of it elucidates the filmmakers' decision to film parts of the lovers' first and final encounters from the knees down.

While a cursory glance at the Conte iranien may make it seem like a tossed-off or ill-considered addition to the collected extras (a conclusion that its visual aesthetics do not exactly discourage), it nevertheless serves an important function in promoting Satrapi's role as source author and co-adapter. By tracing parts of her story to her family, Satrapi links this project to her previous autobiographical work and reaffirms her interest in using real people's lives as material for narrative adaptation. She thus founds her authority as chief storyteller on knowledge of her own family's history, then expands this authority to cover the wider terrain of cultural history; just as Satrapi's familiarity with her personal history cannot be contested, her international audience has little ground on which to challenge her representation of her native culture. She wields this authority for didactic purposes, a goal made evident by a mute Mathieu Amalric assuming the role of model listener. Despite Satrapi's insistence on addressing him as his character, Amalric thus represents the predominantly French audience, who might appreciate her condensed overview of Persian philosophy, provided as a backdrop to the story. In short, this featurette acknowledges the specificity of the narrative's source material - right down to Satrapi's family - even as it spotlights the film's potential for global dissemination as a cinematic ambassador for Iranian culture. Within this context, Satrapi confirms her role as authenticator and cross-cultural interpreter.

In assuming the mantle of director-cum-ambassador, Satrapi adds her name to a long line of filmmakers who recreate a physically and culturally distant land for domestic and/or global consumption. The combination of a multinational cast and a reconstructed foreign setting make Poulet aux prunes an example of what elsewhere I have called integral exoticism: an approach to film narration in which all or most of the 
actors play a nationality or ethnicity not their own, on sets selected or constructed to resemble a real-life, foreign place - possibly during a bygone era - with the aim of projecting it for an audience with little to no firsthand experience of its geography or its people (Kennedy-Karpat 9). This was a common mode of filmmaking during the classical era of French filmmaking - e.g., the myriad adaptations of Russian novels and plays, including Fédor Ozep's Crime et châtiment [Crime and Punishment] (1935) and Jean Renoir's Les Bas-fonds [The Lower Depths] (1936) — as well as in studio-era Hollywood, like the Budapest inhabited by James Stewart and Margaret Sullivan in Ernst Lubitsch's The Shop Around the Corner (1940). Many integral exoticist films are directed by someone like Satrapi, who shares the nationality/ethnicity of the characters on screen.

Claiming a common cultural background becomes even more important in the context of adaptation. A Western director aiming to adapt a preexisting representation of a non-Western country risks (quite possibly justifiable) accusations of cultural appropriation, with any perceived inaccuracies in the finished product interpretable at best as misinformation, at worst as malicious Orientalism. Satrapi's self-adaptation allows Poulet aux prunes to dodge many of these criticisms (while retaining the possibility of selforientalisation), although unlike the examples of integral exoticism from the classical era, Satrapi devotes a great deal of paratextual work to bridging the gulf that separates the non-Western subject of her film from its Western audience.

\section{ACTORS AS TRANSNATIONAL INTERTEXTS}

As a primary requirement of integral exoticism, the international stars of Poulet aux prunes throw a spotlight on the film's exuberantly transnational production. Yet studies of comics-to-film adaptations generally pay little attention to casting and performance, despite Leitch's observation that the selection of actors merits close analysis when drawings inspire a live action film (198). Gray also recognises that stars serve as very powerful intertexts, and audiences familiar with a given star will draw on this knowledge, consciously or not, when faced with new performances (53). For all of these reasons, casting offers a useful interpretive lens for Poulet aux prunes.

Satrapi personally offered French actor Mathieu Amalric the role of Nasser Ali, which he accepted based on his love for the book (Mechanic). With his intense, strangely angled eyes and unconventional features, Amalric is an example of what the French call un joli laid, a person whose unusual look creates an ineffable charisma that transcends yet also inspires physical attraction. Although Leitch claims that 'comic-book adaptations concentrate less on visuals than on concepts like the hero's personality', when it comes to casting, Amalric's atypical appearance forms a cornerstone of his persona and, in turn, makes a direct impact on his characters' personalities (200). Amalric has anchored films - perhaps most notably Julian Schnabel's The Diving Bell and the Butterfly (2007) - but he tends to take on secondary or ensemble roles. Combining commercial films with art house fare, his filmography ranges from Luc Besson's The Extraordinary Adventures of Adèle Blanc-sec (2010) - another comics-to-film adaptation - to Roman Polanski's Venus in Fur (2013) and Alain Resnais's Les Herbes folles [Wild Grass] (2009). His characters (with the arguable exception of the Bond villain he played in Quantum of Solace [2008]) are never entirely bad or good, a moral complexity that also applies to Nasser Ali. Playing Nasser Ali calls upon an actor to behave abominably to his wife and 
family while convincing the audience that he was once capable of (and might even have deserved) real love, requiring, in other words, the blend of sympathy and antipathy that has defined Amalric's screen career.

While Amalric carries the film as Nasser Ali, transnational stars also fill out the roster of secondary characters. For a French audience, the biggest among them is Jamel Debbouze, whose turn as the grocer's assistant in the international hit Le Fabuleux destin d'Amélie Poulain [Amélie] (Jean-Pierre Jeunet, 2001) launched his film career. Debbouze has a dual cameo in Poulet aux prunes: first, the eccentric shopkeeper Houshang, then later as a nameless mystic at Nasser Ali's mother's funeral. His previous work with director Rachid Bouchareb in Indigènes [Days of Glory] (2006) and Hors-la-loi [Outside the Law] (2010) also situates Debbouze as a major player in the twenty-first century evolution of cinéma beur, a strain of French filmmaking that spotlights issues of immigration, social integration, and history of postcolonial populations, themes that combine with his background to give Debbouze a permanent frisson of transnationality.

Debbouze may bring French box-office appeal to the cast, but most of the roles that carry the narrative belong to women. Maria de Medeiros, like Amalric a veteran of secondary roles and ensemble casts, plays the beleaguered wife Faringuisse. Born in Portugal and educated in France, de Medeiros has collected film and television credits from multiple countries, including Quentin Tarantino's Pulp Fiction (1994). Two other women in Poulet aux prunes hail from European film dynasties: Isabella Rossellini plays Nasser Ali's mother, and Chiara Mastroianni plays the adult Lili. As the daughter of Swedish screen legend Ingrid Bergman and Italian director Roberto Rossellini, Isabella Rossellini's heritage alone connotes European sophistication and transnationality; she has reinforced this sensibility with a career that spans both continents and media formats, including at least as many television credits as film appearances. Similarly, the Franco-Italian Mastroianni boasts a family pedigree that includes globally recognised actors Catherine Deneuve and Marcello Mastroianni, although unlike Rossellini's multinational scope, French productions dominate her filmography. Not coincidentally, Persepolis is one of several films in which Mastroianni co-stars with her mother Deneuve, lending their voices to, respectively, Marjane and her mother. The repeat casting of Mastroianni in Poulet aux prunes - this time as Nasser Ali's favoured child Lili-strongly suggests that this character serves as Satrapi's cinematic avatar in the film, especially since her own first-person narration in the book was cut for the screen adaptation.

Among this pan-European cast, the luminous Golshifteh Farahani stands out as the lone Iranian in the role of Nasser Ali's true love, Irâne. This name - the narrative equivalent of a flashing neon sign - points unmistakably to the undercurrent of nationality and identity that flows through Poulet aux prunes by establishing an allegory in which Nasser Ali's lost love also represents the lost homeland. This loss clearly affects presentday Iranian exiles like Satrapi, but the setting in 1958 also underscores what has been lost to time for those who remain there. Of course, Satrapi's book also conveys this sense of loss, but does so by peppering the narrative with historical asides that enhance the story's sociopolitical context.

In the film, casting stresses the significance of national origins, paradoxically, by placing it in the background, contrasting the unified time and place of the film's diegesis with extradiegetic information about actors' personal histories and their professional 
personae. It is, of course, no accident that only one performer in Poulet aux prunes is Iranian, and even less of an accident that her character's name is Irâne. Still, for the story to function properly, the audience must suspend disbelief and accept all of these actors as representations of Iranians. Diversifying the cast in this way indicates a conscious effort to create a kind of international utopia by embracing (and not effacing) the film's integral exoticism. It is also significant that so many members of the cast who can lay claim to a French identity have equal or greater claims on other national identities as well; the transnational hyphenates multiply on screen and subtly point to the Franco-Iranian behind the camera. Casting thus shows once again - along with the Technicolor visuals, the unapologetic melodrama, and the use of remediation - that Satrapi aims to tell an Iranian story through Western intertexts, thus infusing the film with transnationality at every level.

Poulet aux prunes challenges the dominant model of comics-to-film adaptations in a way that opens new avenues for inquiry in adaptation studies. The exceptional freedom that Satrapi claims through self-adaptation interrogates the very notion of fidelity and quells much of the unease generated by the designation of textual authority to the creative team $(\mathrm{s})$ behind any transmedia adaptation. Although transcultural narration threatens to compound this discomfort through gratuitous or uninformed exoticism, Satrapi deploys her own transnationality to bolster her authority and foster a hospitable space within the narrative for intercultural dialogue. Instead of constructing a conversation with herself, Satrapi's self-adaptation invites readers and audiences to engage in dialogue that not only blurs the boundaries between media, but also bridges the gaps between cultures. Her success in parlaying self-adaptation into a filmmaking career apart from her comics makes Satrapi's case even more compelling; situated between the animated, self-adapted Persepolis and the director-for-hire The Voices-her 2014 Indiewood film written by Michael R. Perry and featuring Ryan Reynolds and Anna Kendrick - Poulet aux prunes marks an important juncture in Satrapi's career, connecting the media of graphic novels and cinema, the genres of memoir and fiction, and the various cultures that have contributed to her transnational filmmaking.

\section{NOTES}

${ }^{1}$ The term bande-dessinée is a very rough French analogue for the more recently coined 'graphic novel', but Catherine Labio argues that subsuming all such work under the Anglo-American categories of 'comics' and 'graphic novels' limits the perspective that critics can take on international forms of production whose contexts and histories are not readily comparable. While she makes a strong case, international readers remain likely to encounter translations of Satrapi and other non-Anglophone artists' work in connection with these Anglophone terms. This fact renders impractical the outright rejection of these translations and categorisations for the critique proposed in this essay.

${ }^{2}$ It should be noted that a dearth of US-style superheroes does not mean that French comics-to-film adaptations lack blockbuster budgeting à la Hollywood. For instance, the long-running BD series Astérix et Obélix has become a major film franchise whose four live-action films since 1999 feature internationally known star Gérard Depardieu as Obélix along with appearances from, among others, Roberto Benigni (Astérix et Obélix contre César [1999]), Monica Bellucci (Astérix et Obélix: Mission Cléopâtre [2002]), and Alain Delon (Astérix aux Feux Olympiques [2008]). Another, more recent franchise has adapted the illustrated adventures of Le Petit Nicolas, source texts that cannot properly be called bande dessinée, but are at least as well known for René Goscinny's illustrations as they are for the stories written by Jean-Jacques Sempé.

3 Thomas Leitch offers some useful pathways away from fidelity criticism in 'Adaptation Studies at a Crossroads' (2008). Other alternatives include Linda Hutcheon and Gary R. Bortolotti's effort to splice a 
biological paradigm with fidelity discourse in the arts. Ultimately, what remains clear is that no rethinking of fidelity as a concept will push it to extinction in adaptation studies; as a case in point, the edited volume True to the Spirit (2011) ostensibly aims to reconsider (not to say rehabilitate) fidelity criticism, but I stand with Eckart Voigts and Pascal Nicklas in seeing this collection as less a reexamination of its critical potential than more of the same shopworn applications.

${ }^{4}$ Cobb persuasively argues that the very terms 'fidelity' and 'betrayal' impose a gendered language on discussions of adaptation. However, the issue of gendered discourse vis-à-vis Satrapi as a woman authorartist and filmmaker is beyond the scope of the present essay.

${ }^{5}$ Frank Miller's self-adaptations might provide a counterargument to Leitch's rather bold assertion, but further discussion of this point is beyond the scope of this case study.

${ }^{6}$ For the spoiler-indifferent, the punch line is this: After she is stricken by a mysterious malady, Cyrus and his wife rush their teenage daughter to the hospital, where she gives birth to a baby that no one (not even she) was expecting.

${ }^{7}$ One behind-the-scenes tidbit included in the DVD extras shows Mathieu Amalric, on set as Nasser Ali, failing miserably at playing the violin while his music coach, the crew, and his co-stars attempt to keep a straight face for the rolling cameras.

\section{REFERENCES}

American Splendor. Dir. Shari Springer Bergman and Robert Pulcini. USA. 2003.

Beaty, Bart. "In Focus: Comics Studies Fifty Years After Film Studies." Cinema fournal 50.3 (2011): 106-10. Bolter, Jay David and Richard Grusin. Remediation: Understanding New Media. Cambridge, MA: MIT P, 1999.

Bortolotti, Gary R. and Linda Hutcheon. "On the Origin of Adaptations: Rethinking Fidelity Discourse and 'Success'-Biologically.” New Literary History 38.3 (2007): 443-58.

Christiansen, Hans-Christian. "Comics and Film: A Narrative Perspective." Comics and Culture: Analytical and Theoretical Approaches to Comics. Eds. Anne Magnussen and Hans-Christian Christiansen. Copenhagen, Denmark: Museum Tusculanum P, 2000: 107-121.

Cobb, Shelley. "Adaptation, Fidelity, and Gendered Discourses." Adaptation 4.1 (2010): 28-37.

Crime et châtiment. Dir. Fédor Ozep. France. 1935.

Genette, Gérard. Palimpsestes. Paris, France: Seuil, 1982.

Ghost World. Dir. Terry Zwigoff. USA. 2001.

Higbee, Will and Song Hwee Lim. "Concepts of Transnational Cinema: Towards a Critical Transnationalism in Film Studies." Transnational Cinemas 1.1 (2010): 7-21.

Hors-la-loi. Dir. Rachid Bouchareb. France/Algeria/Belgium/Tunisia/Italy. 2010.

Hulk. Dir. Ang Lee. USA. 2003.

Hutcheon, Linda. A Theory of Adaptation. New York: Routledge, 2006.

Indigènes [Days of Glory]. Dir. Rachid Bouchareb. Algeria/France/Morocco/Belgium. 2006.

Kennedy-Karpat, Colleen. Rogues, Romance, and Exoticism in French Cinema of the 1930s. Madison, NJ: Fairleigh Dickinson U P, 2013.

Kukkonen, Karin. "Comics as a Test Case for Transmedial Narratology." SubStance 40.1 (2011): 34-52.

Labio, Catherine. "What's in a Name? The Academic Study of Comics and the 'Graphic Novel." Cinema Fournal 50.3 (2011): 123-126.

Le Fabuleux destin d'Amélie Poulain. Dir. Jean-Pierre Jeunet. France/Germany. 2001.

Lefèvre, Pascal. "Incompatible Visual Ontologies? The Problematic Adaptation of Drawn Images." Film and Comic Books. Eds. Ian Gordon, Mark Jancovich, and Matthew P. McAllister. Jackson, MS: U P Mississippi, 2007: 1-12.

—. "Some Medium-Specific Qualities of Graphic Sequences." SubStance 40.1 (2011): 14-33.

Leitch, Thomas. "Adaptation Studies at a Crossroads." Adaptation 1.1 (2008): 63-77.

_. Film Adaptation and Its Discontents. Baltimore, MD: Johns Hopkins U P, 2009.

Les Bas-fonds. Dir. Jean Renoir. France. 1936.

Les Herbes folles [Wild Grass]. Dir. Alain Resnais. France/Italy. 2009.

MacCabe, Colin, Kathleen Murray, and Rick Warner. True to the Spirit: Film Adaptation and the Question of Fidelity. New York: Oxford U P, 2011. 
Mechanic, Michael. Marjane Satrapi: Superman Is Boring, Batman Is Hot, Dictators Are Clueless. MotherJones.com 13 Aug. 2012. 18 Apr. 2014. http://www.motherjones.com/media/2012/05/ marjane-satrapi-chicken-with-plums-iran.

Persepolis. Dir. Marjane Satrapi and Vincent Paronnaud. Perf. Chiara Mastroianni, Catherine Deneuve, Danielle Darrieux. France. 2007.

Poulet aux prunes [Chicken With Plums]. Dir. Marjane Satrapi and Vincent Paronnaud. Perf. Mathieu Amalric, Maria de Medeiros, Chiara Mastroianni, Isabella Rossellini, Jamel Debbouze. DVD. Wild Side Video, 2011.

Pulp Fiction. Dir. Quentin Tarantino. USA. 1994.

Quantum of Solace. Dir. Marc Forster. UK/USA. 2008.

Satrapi, Marjane. Persepolis. Paris, France: L'Association, 2007.

. Poulet aux prunes. Paris, France: L'Association, 2004.

The Diving Bell and the Butterfy. Dir. Julian Schnabel. France/USA. 2007.

The Extraordinary Adventures of Adèle Blanc-Sec. Dir. Luc Besson. France. 2010.

The Shop Around the Corner. Dir. Ernst Lubitsch. USA. 1940.

The Voices. Dir. Marjane Satrapi. USA/Germany. 2014.

Venus in Fur. Dir. Roman Polanski. France/Poland. 2013.

Voigts, Eckart and Pascal Nicklas. "Adaptation, Transmedia Storytelling and Participatory Culture." Adaptation 6.2 (2013): 139-42.

\section{ACKNOWLEDGEMENTS}

The author wishes to thank L'Association for graciously granting permission to reprint portions of Marjane Satrapi's book Poulet aux prunes. Further thanks go out to the manuscript's anonymous readers for their helpful points, to the attendees of the 2013 Northeast Modern Language Association convention who commented on early efforts to unpack Poulet aux prunes, to Michael Meeuwis for insightful comments on an earlier draft, and to Daniel Leonard for a thorough and thoughtful critique along with steadfast moral support during the completion of this essay. 